interest to good students. From a library service perspective, such programs can redirect the workload of the public services staff by reducing the amount of required individualized attention to young patrons. Additionally, the subtle recruiting effort provides a rationale for excellent library service to high school users that all library employees can understand and justify to colleagues. But most important for our library, the willingness of librarians to suggest and implement this program has demonstrated to our administration that we are in- deed "team players" and concerned about the institution as a whole.

Academic librarians need to be constantly seeking connections between the goals of excellent library service and specific goals and objectives of the institution. Making these connections will require experimentation with programs and promotion of the results. We have found that a role in recruitment, however subtle, provides this kind of connection between our library and its institution.

\title{
Library earns high marks
}

\author{
By Jon Eldredge \\ Chief of Collection and Information Resource Development \\ Medical Center Library, University of New Mexico
}

\section{Seton Hill College wins a John Cotton Dana Public Relations special award.}

\begin{abstract}
A ated that resourcefulness and creativity are the most essential ingredients in a successful public relations program. This year the Reeves Memorial Library at Seton Hill College in Greensburg, Pennsylvania, has won a Special Award in ALA's John Cotton Dana Library Public Relations Award Contest. This annual contest, sponsored jointly by the H.W. Wilson Company and the LAMA Public Relations Section, has offered recognition to libraries for their outstanding promotional programs since 1946. The contest features a John Cotton Dana Award for a superb, comprehensive annual PR program and a Special Award for a discrete aspect of an overall PR program. Seven strong entries from academic libraries competed for an award in the contest this year.

The library at Seton Hill College won this award for its role in producing a series of simple,
\end{abstract}

modestly-priced, yet attractive bookmarks. Financing the printing costs of these bookmarks represented the only significant expense involved in this project. The librarians at Seton Hill College wanted promotional materials for their user groups which would be more appropriate than those items produced commercially for other types of libraries. Many academic librarians share this concern for utilizing promotional materials that will be suitable for their users.

Seton Hill College provides an undergraduate liberal arts curriculum to its 900 students. Greensburg is a small city located 30 miles southeast of Pittsburgh in the rural foothills of the Allegheny Mountains. Like many undergraduates, the Seton Hill College students tend to possess an incomplete conception of what services a library might be able to supply. It was within this context the library wanted to promote its services. "Most of the pro- 
motional materials available to libraries were directed toward a younger, more recreational reading-oriented audience," notes library director Deborah Pawlik. Budgetary constraints initially seemed to prevent the library from realizing its goal of producing high-quality promotional materials designed to appeal to a college population. Through her regular faculty contacts, however,

\section{Small fuzzy animals}

\section{were ruled out.}

Pawlik discovered an opportunity. Art professor Suzanne Harding needed a simulated advertising project for her students in a graphic arts course. After expressing an interest in library involvement with the project, Harding designed a graded assignment for the students in which the library would assume the role of an advertising firm "client" in need of promotional items. Pawlik would present the class with a detailed description of her organization's advertising requirements. Bookmarks were chosen as the medium for these materials due to their reasonable production cost.

Prior to Pawlik's appearance before the class, the library staff carefully defined the goals and objectives for this project. The librarians realized that without a combination of thorough planning and a clear articulation to the students of what was needed, the project would be far less successful. The staff even provided examples of materials it viewed as inappropriate so students could develop a clearer conception of what kinds of materials might be applicable in an academic environment. For instance, the director ruled out any designs that were "cute" or contained "small fuzzy animals." Instead, she conveyed the idea the library wanted bold, eye-catching graphic designs on the bookmarks. The students were required to include the proper name and address of the library, the date of the project, and their own names on the bookmarks.

Pawlik's presentation included some simple education about the full range of services and resources available from the library. She entitled the project "If you think books are all we've got... you've missed a lot" to remind students of the many aspects of the library they might want to promote in their projects. She challenged them to take genuine risks in their creative efforts. Pawlik also invited the students to collect more information, as needed, from the library staff if they had further questions while completing the assignment.

The librarians at Seton Hill College were uncertain about what to anticipate from the students' projects. Pawlik told me that she "was not expect- ing much but was delighted with the results" when she met with the class for a revision critique. Most bookmark prototypes needed only minor revisions. Pawlik later attributed this surprisingly high level of success to the library's planning and communication processes, as well as to a dynamic professor who instilled enthusiasm in her students. A few students seemed to misunderstand the concept and parameters of the assignment. One student, for example, drew a computer more akin to a video game arcade device than a library computer. Another student exaggerated the library's ability to provide reference information on demand. Both Professor Harding and the library staff were thrilled by the students' final revisions of the bookmarks. Most designs were considered good enough for offset production (total cost $=\$ 340$ ) and library distribution.

Success in this pilot project has spurred the library staff and Professor Harding to pursue similar assignments with future graphic arts classes. Deborah Pawlik suggests that academic librarians wishing to adopt this bookmark project consider some of the additional insights she has gained from this experience. First, students must have a clear idea of what the library expects. Their direct interaction with a librarian in class acting as their client will facilitate this communication process. Second, students are not highly-skilled advertising agency artists. Even when they are motivated by a course grade they will be distracted from their work by competing priorities such as assignments for other classes. Hence, the quality of their library projects may be uneven, encompassing a range of grades from A to F. Only one out of twenty student projects may deserve utilization by the library. Third, the library always should grant recognition to the students. Placement of the students' names on the promotional items, letters of thanks, a library display featuring the projects, and other forms of appreciation are important.

The contest judges were more impressed by the quality of the Seton Hill College entry than by any quantity of money spent or the slickness of its promotional materials. They recognized the ability of the librarians at Seton Hill College to effectively utilize available on-campus resources in ways which would benefit all parties involved with the project. In addition, the judges praised the library for its capable administration of the program through clearly articulated goals and objectives. The library achieved three goals connected with the project: 1) to promote new library materials and services; 2) to involve students in the production of these promotional items; and, 3) to make the library and librarians more visible on campus.

The judges thought the replicability of this project at other academic libraries, plus the simplicity of the implementation, constituted two major strengths of the entry. Overall, they viewed the Seton Hill College project as a creative solution to a typical academic library problem compounded by 

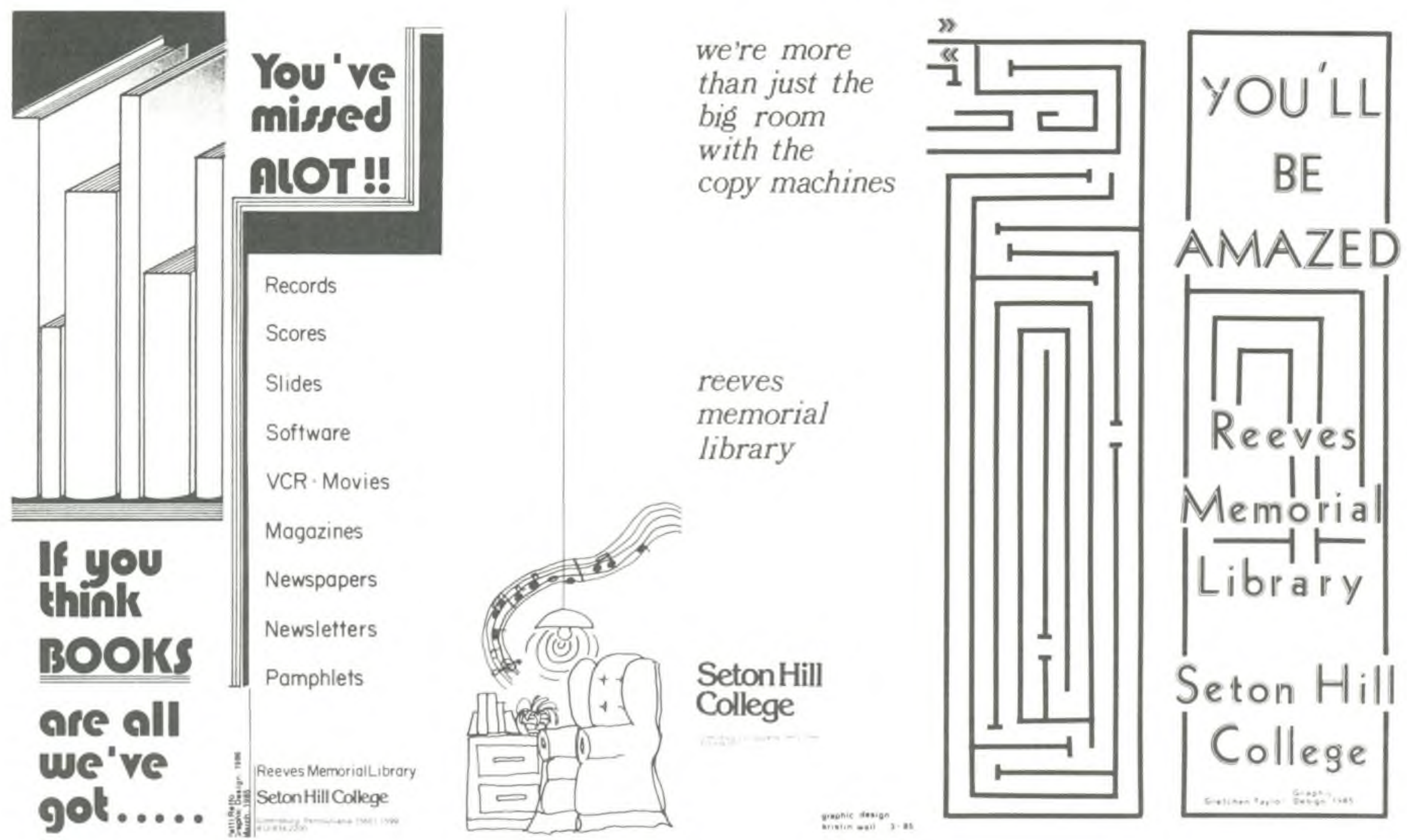

Award-winning bookmarks from Seton Hill College Library.

the additional disadvantage of accentuated economic limitations. It seems that entries received from academic libraries during recent years have displayed greater and greater degrees of sophistication. This same pattern generally has been observed in entries from other types of libraries as well. This trend has brought more intense competition between entries in the final judging rounds, which typically culminate in narrowly-decided majority votes for the winners. In spite of this trend, the Seton Hill College entry so impressed the judges that it won by a unanimous vote.

\section{Advice to entrants}

The ultimate success of entries that have reached the final rounds of judging will be determined by whether or not the entrants pay attention on their application forms to crucial details. Future entrants may benefit from a cognizance of what judges consider to be pivotal components of contest entries. Toward the end of the five-day judging session most entries have been eliminated due to weaknesses in program goals and objectives statements. Clear, realistic and adequately described statements on goals and objectives in entries have genuine advantages when crossing these final judging hurdles. Goals must represent genuine achievements in spite of their realism. An entry this year, for example, was quickly eliminated when judges realized its goals could be very easily attained. Contest entries can be significantly strengthened if the relationships between goals, objectives, and even target groups can be defined precisely. Most entries lack either adequate amounts or appropri- ate kinds of information about their PR program goals and objectives.

Program evaluation represents the second most common problem area for contest entries. Evaluation methods must sufficiently and legitimately document PR program success. Entrants should be advised that the judges possess considerable expertise on evaluation processes; they can quickly identify misapplications of these methods. Statistical evidence of PR programs achieving goals and objectives effectively reinforce the evaluation section of the entries. Yet, statistics serve as meaningful indicators of success only when entrants demonstrate the practical linkages between the numbers and the real world. This does not mean the judges require epistemological discussions by entrants on the soundness of their evaluation methodologies. They simply expect entrants to observe elementary conventions of statistical applications in their program evaluations. Intuitive evaluation techniques may enhance, but never can replace more concrete forms of program assessment. Evaluations based solely upon intuitive statements such as "many positive remarks," "program was well-attended," "a great success," "we believe," "good image," or "engendered goodwill" will encounter problems in the judging process. Flowery phraseology, in short, will not substitute for appropriate evaluation documentation.

Well-organized scrapbooks that efficiently communicate information about entries always fare better in the judging process. The five-day judging week certainly imposes time constraints. Judges unable to obtain vital information quickly due to 
the presence of lengthy narratives or fragmented responses to application form questions may assume crucial facts are missing and eliminate such entries. Responses to questions should be addressed directly and be characterized by their conciseness. Any supplementary details deemed important enough for inclusion should follow the main points in the responses. The best scrapbooks seem to begin

\section{There are no simple formulas for PR success.}

with a more general perspective and then work toward more specific information in their organizational layouts. Entrants can achieve this effect with devices like tables of contents, clearly marked sections, or introductory paragraphs that resemble journal abstracts.

Prospective entrants often wonder about the acceptable parameters of conciseness and completeness for their entries. Personal examination of winning entries will best answer these questions. The examples of previous winners also will help future entrants more clearly understand what judges look for in winning entries. Perusal of the winning entries reveal that these entrants carefully followed contest rules, focused their PR programs upon no more than a few unifying themes, and identifed key target groups. Programs more closely identified with education, fundraising, bond issues, or grant projects than with PR are notably absent from the winners' circle.

At each ALA Annual Conference the winning entries can be viewed at the Swap'n'Shop program or on display in the exhibit area. Winning entries from the past two years may be obtained via interlibrary loan from the ALA Headquarters Library. An annual ALA publication entitled Great Library Promotion Ideas also describes the PR programs of winning and notable contest entries. A review of former winners' entries by prospective entrants always introduces the risk of their narrowly defining the scope of possible PR projects. Last year an entry described a PR program which had blatantly combined the ideas of previous winners into the entrant's own project. The judges quickly eliminated this hybridized entry for lack of originality. There are no simple formulas for success in the contest. This judge can only offer guidelines and suggestions.

Academic libraries that serve a particular mission or user group should contemplate entering the Special Library category instead of the Academic Library category in the contest. This year an academic medical library won an award by entering the contest in the Special Library category. More information about this entry submitted by the University of Texas Health Science Center at San Antonio can be found in the August 1986 issue of the Medical Library Association News. Additional information on how academic libraries might compete in the contest will be found in articles pub-

\section{WHEN THE QUESTION IS SERVICE}

\section{THE ANSWER IS AMBASSADOR}

- FIRM ORDERS

- CONTINUATIONS

- apPROVAl PLANS

- BINDING SERVICES

- ON-LINE ORDERING

"serving college and university libraries for over 12 years"
Ambassador
Book Service, INC.
42 CHASNER STREET
- HEMPSTEAD, NEW YORK 11550
toll free
$800 \cdot 431-8913$
in New York call collect
(516) 489-4011 
TABLE 1

ACADEMIC LIBRARY AWARD RECIPIENTS, 1948-1968

\begin{tabular}{ll}
\hline \hline Year & Library \\
\hline 1948 & Kent State University \\
1949 & Brooklyn College \\
1952 & Brooklyn College \\
1953 & Dartmouth College \\
& State Teachers College (Trenton, N.J.) \\
1954 & Dartmouth College \\
1955 & Oklahoma City University \\
1957 & University of California, Berkeley \\
1958 & U.S. Air Force Academy \\
1959 & Brooklyn College \\
1960 & University of California, Los Angeles \\
1961 & U.S. Air Force Academy \\
1962 & U.S. Military Academy (West Point) \\
1964 & (Georgia) State College, Savannah \\
1965 & Teachers College, Columbia University \\
& (Georgia) State College, Savannah \\
1968 & South Carolina State College \\
& U.S. Air Force Academy \\
\hline
\end{tabular}

Note: The names of more recent winners appear in other articles by the author.

lished in C $b R L$ News, June 1983, July/August 1984, and December 1985. Entry forms as well as specific details on the contest are available from Jon L. Clayborne, Library Relations Coordinator, The H.W. Wilson Company, 950 University Avenue, Bronx, NY 10452; (212) 588-8400, x708.

\section{Success story}

The librarians at Seton Hill College were proud of the students' bookmarks but they were not sure that this modest project could win an award. They entered the contest mainly for experimental purposes. They believed that the entry application process and the judges' evaluations alone would improve their public relations efforts. One librarian noted that "the contest entry form makes one appreciate the complex relationship between a single $\mathrm{PR}$ project and a broader perspective on the overall PR activities pursued by a library."

As this article goes to press the librarians at Seton Hill College already are planning another project they hope to enter into a future John Cotton Dana Library Public Relations Award contest. They point to many favorable results which can be attributed to winning the award. For one, the completion of the entry process has made them more aware of the multifaceted nature of public relations rather than just the obvious element of publicity. Other professionals within the area have praised them for their accomplishment. The local news media has publicized Seton Hill College's winning an award as well. The award has raised morale on campus among all persons associated either directly or indirectly with the library. Receiving recognition at the elegantly-catered awards reception attended by several hundred leaders in the library profession also suggest other impressive, though intangible benefits for the winners. Deborah Pawlik told me in June that the Seton Hill College alumnae are enthusiastic about the library winning this prestigious national award. Furthermore, Seton Hill College plans to completely renovate the Reeves Memorial Library and build a twostory addition to the present structure in the coming academic year. "Libraries receive too few awards," Pawlik said, adding, "this award has given us a chance to focus attention upon our services and needs."

Until recently most academic librarians assumed that the John Cotton Dana Library Public Relations Award contest was an activity reserved exclusively for public libraries. When academic libraries began to attract attention with their awards a few years ago, many academic librarians naturally thought the appearance of these winners reflected a change in contest policy. Yet, a review of the contest history indicates a tradition of academic library involvement and noteworthy success. Between 1948 and 1968 a total of 19 academic libraries won awards. Table 1 lists those early winners. The secrecy surrounding the contest judging process during the early years makes it difficult to 
know the exact backgrounds of all the judges. The documentation available suggests that most judges were from public libraries. The predominance of public librarians on the judging panel may have contributed to the widespread notion that no other types of libraries could enter the contest. It appears that in 1958, though, Morris A. Gelfand from Queens College in New York became the first academic librarian to serve as a contest judge. During 1962 Sidney Forman from the U.S. Military Academy was the second known academic librarian to serve as a contest judge.

Academic librarians in recent years have been regular members on the judging panel. For the first time in contest history an academic librarian will chair the judging committee this year.

Contest scrapbook or media entries need not be glamorous or expensive to win an award. The Seton Hill College entry scrapbook cost $\$ 4.00$. The colored paper and the graphic designs used for mounting the bookmarks in the scrapbook were obtained from publishers' catalogs. This pattern of resourcefulness has characterized many winning entries throughout the forty-year history of the contest. Pawlik has remarked that "there are many ways to do things without buying materials out in the marketplace." Indeed, the librarians at Seton Hill College certainly have proven that even a modest PR program can achieve the recognition it deserves.

Editor's note: Jon Eldredge currently serves as chair of the Dana Awards Committee.

\title{
Dan Bricklin's Demo Program
}

\author{
By Keith J. Stanger \\ Coordinator, Access Services \\ Eastern Michigan University
}

\section{Reaching students and faculty with a microcomputer-based "slide show."}

\begin{abstract}
M any librarians are working to develop their clients' understanding of computer database searching. Central to this understanding are the principles underlying the formulation of a search strategy to retrieve information from computerreadable data files. However, before attempting to teach searching principles, presentation of a general overview of database searching concepts and procedures is often helpful.

Many methods are being employed to provide this introduction to what database searching is, how to prepare for it, and what actually occurs during a database search-lectures, demonstrations, printed brochures, video tapes, computer-
\end{abstract}

assisted instruction. With a relatively inexpensive computer program written for the IBM PC (and MS-DOS compatibles) I have found that I can quickly put together both a microcomputer-based tutorial that introduces database searching as well as a simulation of an actual database searchwithout my learning a programming language.

Dan Bricklin's Demo Program (as the co-creator of VisiCalc aptly named his new program) is a prototyping program. It was designed to help software authors as well as non-programmers to conceptualize new programs, describe them to others, and teach the final product. For example, with Dan Bricklin's Demo Program (called Demo from here 